\title{
The Application of Zinc Oxide Nanoparticles as An Eco- Friendly Inhibitor for Steel in Acidic Solution
}

\author{
Reema H. Al-Dahiri ${ }^{1}$, Aisha M. Turkustani ${ }^{1,2}$, Mohamed Abdel Salam ${ }^{1}$ \\ ${ }^{1}$ Chemistry Department, Faculty of Science for Girls, King Abdulaziz University, P.O. Box 80200, \\ Jeddah 21589, Saudi Arabia. \\ ${ }^{2}$ Chemistry Department, Faculty of Science for Girls, Jeddah University, Jeddah, Saudi Arabia \\ *E-mail: masalam16@ hotmail.com
}

doi: $10.20964 / 2020.01 .01$

Received: 1 September 2019 / Accepted: 23 October 2019 / Published: 30 November 2019

In this study, zinc oxide nanoparticles were prepared using a natural extract of Myrrh as green capping agent. The synthesized ZnO-NPs (Zinc Oxide Nanoparticles) were characterized using XRD and scanning electron microscopy, and the results revealed the synthesis of hexagonal wurtzite ZnO-NPs. The corrosion inhibition of steel in $1.0 \mathrm{M} \mathrm{HCl}$ using an aqueous extract of natural Myrrh and the greensynthesized $\mathrm{ZnO}-\mathrm{NPs}$ was investigated at various concentrations using electrochemical impedance spectroscopy (EIS) measurements and potentiodynamic polarization (PDP). The results revealed that the corrosion inhibition process is exponentially increased with the inhibitor concentrations, and an inhibition effectiveness of $92 \%$ could be acquired. Polarization curves showed that the eco-friendly inhibitors perform as a cathodic inhibitor. Consequently, the obtained inhibition efficiency values derived from all chosen analysis techniques were in reasonably good agreement.

Keywords: corrosion; steel, Myrrh, green synthesis, zinc oxide nanoparticles

\section{FULL TEXT}

(C) 2020 The Authors. Published by ESG (www.electrochemsci.org). This article is an open access article distributed under the terms and conditions of the Creative Commons Attribution license (http://creativecommons.org/licenses/by/4.0/). 